J. Dairy Sci. 103:8708-8708

https://doi.org/10.3168/jds.2020-103-9-8708

(c) 2020 American Dairy Science Association ${ }^{\circledR}$. Published by Elsevier Inc. and Fass Inc. All rights reserved.

\title{
Corrigendum to "Short communication: Economic impact among 7 reproductive programs for lactating dairy cows, including a sensitivity analysis of the cost of hormonal treatments" (J. Dairy Sci. 103:5654-5661)
}

\section{A. Ricci, M. Li, P. M. Fricke, and V. E. Cabrera}

On page 5656, in Figure 1, panel E, the sequence of events was incorrect; the correct sequence (changes in bold) is GnRH-PGF-GnRH-GnRH-PGF-PGF-GnRH-TAI-Preg. Check. The corrected figure is shown below.

The authors regret the error.

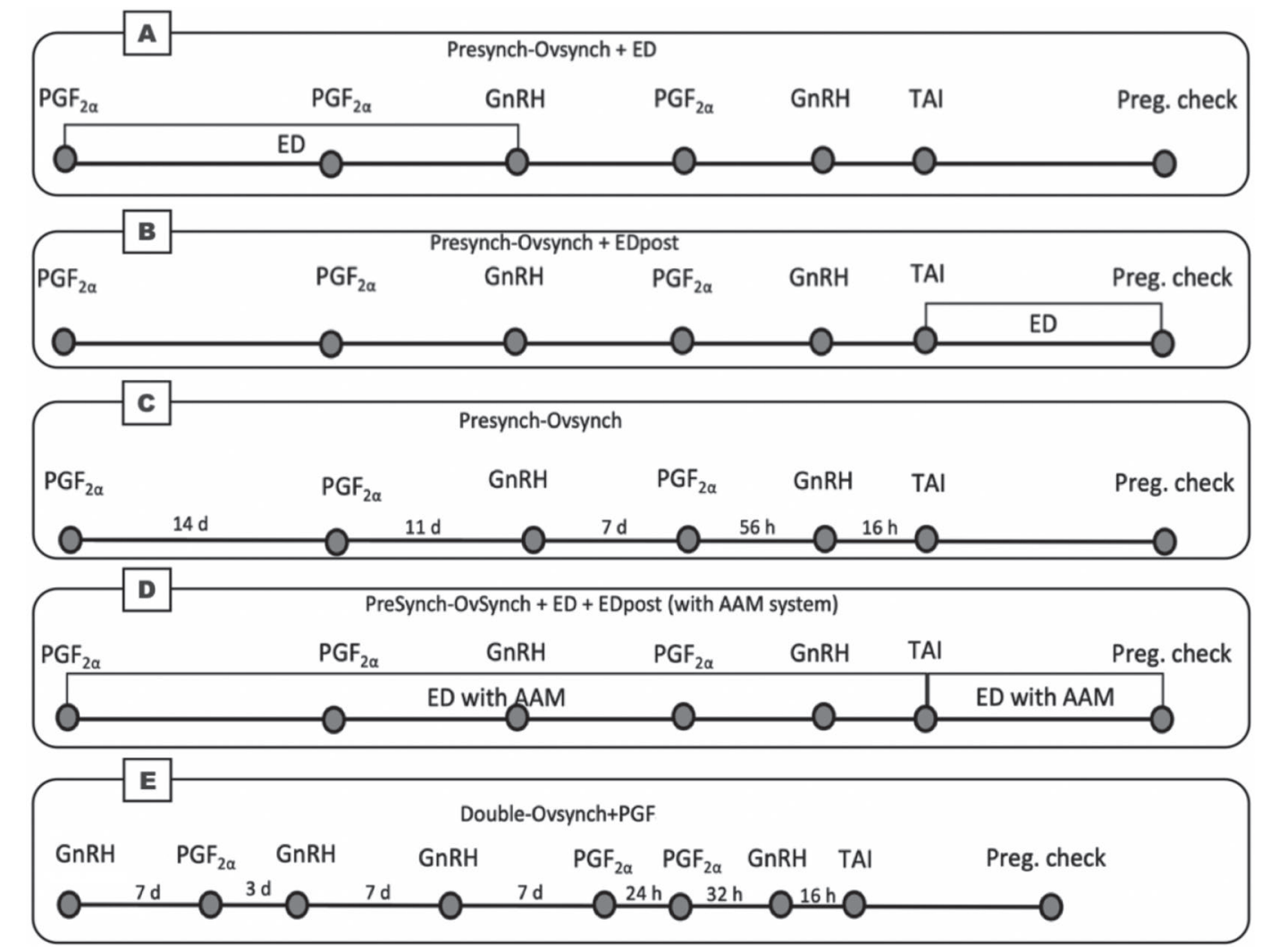

Figure 1. Schematic diagram of treatments used in this study. (A) Presynch-Ovsynch+ED; (B) Presynch-Ovsynch+EDpost; (C) PresynchOvsynch; (D) Presynch-Ovsynch+ED+EDpost (with AAM system); and (E) Double-Ovsynch+PGF. ED = estrus detection; TAI = timed AI; EDpost $=$ estrus detection performed after first AI; AAM = automated activity monitoring; Preg. = pregnancy.

\section{REFERENCES}

Ricci, A., M. Li, P. M. Fricke, and V. E. Cabrera. 2020. Short communication: Economic impact among 7 reproductive programs for lactating dairy cows, including a sensitivity analysis of the cost of hormonal treatments. J. Dairy Sci. 103(6):5654-5661. https://doi.org/10.3168/jds .2019-17658. 